\title{
Robotic and advanced laparoscopic surgical training in European gynaecological oncology trainees
}

${ }^{1}$ Gan Carmen MRCOG, ${ }^{2}$ Bossart Michaela MD, ${ }^{3}$ Piek Jurgen PhD, ${ }^{4}$ Halaska Michael MD, ${ }^{5}$ Haidopoulos Dimitrios MD, ${ }^{6}$ Zapardiel Ignacio PhD, ${ }^{7}$ Grabowski Jacek P. PhD, ${ }^{8}$ Kesic Vesna MD, ${ }^{9}$ Kimmig Rainer MD, ${ }^{10} \mathrm{Cibula}$ David PhD, ${ }^{11}$ Lambaudie Eric MD ${ }^{12}$ Verheijen René PhD, ${ }^{1,13,14}$ Manchanda Ranjit PhD.

1 Department of Gynaecological Oncology, Royal London Hospital, Whitechapel, London, UK

2 Department of Obstetrics and Gynecology, University of Freiburg, Freiburg, Germany

3 Comprehensive Cancer Center South Location Catharina Hospital, Eindhoven, The Netherlands

4 2nd Medical Faculty of the Charles University, Prague, Czech Republic

5 1st Department of Obstetrics and Gynecology, Gynecologic Oncology Unit, Alexandra Hospital, Athens, Greece

6 Gynaecologic Oncology Unit, La Paz University Hospital, Madrid, Spain

7 Department of Gynecology, European Competence Center for Ovarian Cancer, ChariteUniversity Medicine of Berlin, Berlin, Germany

8 Medical Faculty, University of Belgrade, Department of Obstetrics and Gynecology, Clinical Center of Serbia, Belgrade, Serbia

9 Clinic of Obstetrics and Gynecology, Medical Faculty, University of Duisburg-Essen, Germany

10 Oncogynecological Centre, Charles University Hospital, Prague, Czech Republic, Prague

11 Paoli Calmettes Institute, Marseille, France

12 Division of Surgical and Oncological Gynaecology, University Medical Center Utrecht, Utrecht, The Netherlands

13 Barts Cancer Institute, Queen Mary University of London, UK

14 Department of Women's Cancer, EGA Institute of Women's Health, University College London, UK 
Corresponding author:

Dr Ranjit Manchanda,

Consultant Gynaecological Oncologist

Department of Gynaecological Oncology

Bartshealth, Royal London Hospital

$10^{\text {th }}$ Floor, The Bridge

Whitechapel, London E1 1BB

Tel: +442035942053

Fax: +44 2035942792

Email: r.manchanda@ucl.ac.uk

Word count: 2146

Funding: This project was funded from a European Society of Gynecological Oncology (ESGO) grant to ENYGO

Disclosure statement: The authors have declared no conflict of interest. 


\begin{abstract}
$\underline{\text { Abstract }}$
Introduction

Advanced minimal access surgical training is an important component of training in gynaecological oncology(GO). Europe-wide data on this topic are lacking. We present data on availability and trainee experience of advanced laparoscopic surgical(ALS) and robotic surgical(RS) training in GO across Europe.
\end{abstract}

\title{
Method
}

A prospective web-based anonymised survey of European GO trainees was sent to ENYGO members/trainees. It included socio-demographic information, and specific questions pertaining to training experience/satisfaction in laparoscopic-\&-robotic surgery. Chi-square test was used for evaluating categorical variables and Mann Whitney/Kruskal Wallis (nonparametric) tests for continuous variables between two/more independent groups.

\section{Results}

$113 \mathrm{GO}$ trainees from 29 countries responded. The mean age was 35.2(S.D=6.1) years, $59.3 \%$ were men, $40.7 \%$ women and $46 \%$ were in accredited training posts. ALS/RS training was offered in only $43 \% / 23 \%$ of institutes and $54 \% / 23 \%$ trainees had undergone some form of formal or informal training. $62.4 \%$ felt RS should be a formal component of GO training programmes. $61 \% / 35 \%$ planned to go outside their institute for ALS/RS training. Trainees rating (1-5 scale) of their open-surgery/ALS/RS skills (3.3/2.6/1.9) and training experience (3.5/2.8/2.1) respectively were higher for open-surgery than ALS/RS $(p<0.0005)$. Accreditedposts were more likely than non-accredited posts to offer ALS training $(60 \% / 31 \%, p=0.002)$, formal training schedules $(27.9 \% / 4.4 \%, \mathrm{p}=0.003)$ and use of logbooks $(46 \% / 23 \%, \mathrm{p}=0.035)$.

\section{Conclusion}

Training and experience in ALS/RS are poorly rated by GO trainees across Europe and only few centres offer this. There is an urgent need to expand and harmonise training 
opportunities for ALS and RS. Most trainees want RS included as a formal component of their training.

Keywords: Gynaecological oncology trainees, robotic surgery, accredited, survey 


\section{Introduction}

Advanced laparoscopic surgery (ALS) in gynaecological oncology(GO) has made great strides since the 1990s when Dargent(1) and Querleu(2) first described this. . FDA approval of the da-Vinci Surgical System (Intuitive Surgical Corporations, USA) for gynaecological surgery has led to its proliferation and sharp increase in uptake worldwide. (3) Both ALS and robotic surgery(RS) now play an increasingly important role in the surgical treatment of gynaecological cancers and are the mainstay for primary surgery in endometrial and cervical cancers. Compared to laparotomy minimally-invasive surgery is associated with a shorter hospital stay, less blood loss, better cosmesis and similar/lower complication rates but longer operating time and steeper learning curve.(4-5) This further magnifies the importance of ALS/RS being an essential component of any gynae-oncology training programme. Additionally, it is well established that treatment by accredited and appropriately trained gynaecological oncologists is associated with improved survival outcomes for patients with gynaecological cancer.(6-7)

We have previously reported on the satisfaction, training needs/experience, differences in training systems, and training environment for European GO trainees and highlighted the disparity as well as importance of accreditation and harmonisation of training in GO across Europe.(8-10) The European Society of Gynaecological Oncology(ESGO) in conjunction with European-Board and College of Obstetrics-\&-Gynaecology(EBCOG) have made important strides to streamline training by accrediting 29 European centres and recognising national training programmes of the Netherlands and United Kingdom(UK). However, a number of countries still don't recognise GO as a separate sub-specialty and lack a standardised training curriculum. Training opportunities and standards vary significantly across European countries and have been categorised as: well-structured, moderately structured, and loosely structured training systems,(11) details of which have been reported by us earlier.(12) The use of RS is not yet widespread across European cancer centres and 
the number offering GO training in RS/ALS is unknown. Data on trainee experience and structure of training in ALS/RS across Europe are also lacking. The European Network of Young Gynaecological Oncologists(ENYGO) has 650 members and is the principal network (within ESGO) for juniors/trainees in GO and related subspecialties across Europe. We for the first time report on the availability of and trainee experience in ALS/RS in GO across Europe.

\section{Method}

In order to maximize the ability to capture data from all trainees undergoing some form of GO training in Europe, an anonymous web-based survey (supplementary table-1) was sent to 650 ENYGO members as well as trainee lists ascertained through formal/informal networks outside ESGO, via ENYGO national representatives $(n=900)$. Although, there is no official register/record/database of GO trainees to access in most individual European countries, where this existed (UK, the Netherlands), all trainees were surveyed. The development of the questionnaire is described in supplementary table-2.

The survey included demographic/general information including, age, gender, country of training, type of training institute, current post, experience/level of training and accreditation status of the training centre. Specific sections on ALS and RS covered training experience/structure/assessment process. Trainees were asked to rate their training and skills in open, ALS and RS using a 1-5 Likert scale (1=poor, 5=excellent).

Demographics were described using descriptive statistics. Mann Whitney/Kruskal-Wallis (non-parametric) tests compared continuous variables between two/more independent groups. Chi-squared/Fisher's test compared independent categorical variables. Analyses were performed on SPSS version-19.0 (IBM-Corp. 2010.Armonk,NY) 


\section{Results:}

A total of 167 trainees from 30 countries responded of which 44 were excluded (as not currently in GO training) and 113 were included in our analysis. The mean age of trainees=35.2years $(S D=6.1)$. The majority respondents were from France(15.9\%), UK(11.5\%), Italy(8.0\%) and Germany(7.1\%) (supplementary table-3). Of these 55\% worked in cancer centres, $29 \%$ in university hospitals and $16 \%$ in district hospitals. Basic demographics of respondents are illustrated in table-1.

Trainees rated both their skills and training experience in open surgery higher than ALS, which in turn was rated higher than $\mathrm{RS}(\mathrm{p}<0.005$,table-2). Seventy-six $(67.9 \%)$ institutions undertook ALS and only 26(29.5\%) undertook RS procedures $(p<0.005)$, but of these only $49 / 76(64.5 \%)$ or $43 \%$ overall institutes offered training in ALS and 10/26(38.5\%) offered training in RS respectively (table-2). Where training for these surgical modalities were not in place, $22(36.7 \%)$ and $17(27.0 \%)$ institutions were planning to offer training in ALS and RS in the future within a mean(SD) of 1.1(1.3) and 1.7(2.1) years respectively. Significantly more trainees planned to go to an institution other than their current workplace to be trained in ALS[69(63.9\%)] than $R S[39(47.0 \%)], p=0.03$. Of these $20(29 \%) / 5(12.5 \%)$ proposed to go to an institute outside their country for training in ALS/RS respectively.

Sixty-one (56.0\%) trainees had undergone some form of formal/informal training in ALS compared to $26(30.6 \%)$ for $\mathrm{RS}(\mathrm{p}<0.005)$. A detailed comparison of training availability/structure in ALS/RS is given in table-3. Mean number of ALS/RS cases observed, assisted or performed as primary surgeons are tabulated in table-3. A sub-analysis of training by centre accreditation showed that accredited compared to non-accredited institutions were more likely to offer sub-specialty training in ALS (31/52[59.6\%] vs. 18/59[30.5\%], $p<0.005)$ and undertake RS (17/42[40.5\%] vs 9/46[19.6\%], $p=0.04)$ respectively. In the ALS-group, accredited compared to non-accredited centres were also more likely to offer formal training schedules (12/43[27.9\%] vs. $2 / 45[4.4 \%]), p<0.005$ and use of logbooks for training assessment (17[45.9\% vs. 10/44[22.7\%]), $p=0.04$. 
Table-4 highlights details on the availability and use of robotic systems within European institutes offering this facility. Interestingly, 53/85(62\%) trainees (41\% non-accredited and $21 \%$ accredited, $p<0.005)$ felt that RS should be included as a formal component of GOtraining and26.5\% surveyed felt RS should replace ALS as gold-standard in certain GO procedures (supplementary table-4).

\section{Discussion}

To the best of our knowledge this is the first broad based report of ALS and RS training in GO across Europe. Despite the established role and importance of minimal-access surgery in the surgical management of gynaecological cancer, it is unfortunate that only $43 \%$ of institutes overall offered training in ALS and 9\% in RS. Even where institutional facilities existed, only $64.5 \%$ offered training in ALS and $38.5 \%$ in RS.

Reasons for this may be multifactorial, with limited minimal-access infrastructure, high costs and lack of advanced minimal-access skills amongst an older generation of trainers being possible factors. While robotic systems provide advantages of three-dimensional visual fields, increased maneuverability, better ergonomics and reduction in surgeon's fatigue with prolonged operating procedures over traditional laparoscopy(13), the lack of perceived tactile feedback may be a limitation. In addition, the high economic cost of establishing and maintaining a robotic programme is a major factor preventing its widespread adoption. Additionally, the likely recent establishment of robotic programmes in some institutes with trainers themselves going through their learning curve could lead to limited opportunities for trainees. However, the poor availability of ALS training is glaring and needs urgent addressing. While training in radical procedures is a standard part of the GO training curriculum, ESGO/RCOG curricula do not specifically mandate the route for undertaking these procedures or need for training in ALS/RS. Given the major advantages of minimal- 
access surgery for some GO procedures, it is important for training curricula to be revised to address this lacuna. RS has been found to be less cost effective than ALS but may be more cost-effective than open surgery(14-16). The additional cost relates primarily to the substantial fixed cost of the robotic system $(\$ 1.5 \mathrm{M}-1.75 \mathrm{M})$, annual maintenance $(17)$ and the cost of training the surgical team $(\$ 49000-\$ 550000)(18)$. Costs of RS decrease with increasing caseload and increasing surgical experience(17). While current evidence shows similar perioperative outcomes for RS and ALS, data clearly show lower morbidity for minimally-invasive surgery compared to laparotomy in early endometrial and cervical cancers. Given cost implications, great variation in health systems and routes/streams of funding for health programmes across Europe, majority of institutions may find it difficult/be unable to establish RS training programmes in GO. However, establishing infrastructure for ALS is less capital intensive than RS $(17,19)$ and should be more feasible for cancer centers.

Although all gynaecological RS procedures can be performed by ALS, it has a steeper learning curve $(17,29)$ and difficulty associated with the fulcrum effect operating with strait sticks. Many surgeons may feel ill-equipped to perform these procedures safely. RS may also offer an advantage in the morbidly obese population. While ideally accredited programmes should offer standardized training in both RS and ALS, it can be argued that this need not be mandatory but institutions should at least offer training in one form of minimally-access surgery. The SAGES-MIRA robotic surgery consensus group(20) has detailed training and credentialing issues in RS and the ESGE (European-Society of Gynaecological-Endoscopy) in collaboration with EAGS (European-Academy of Gynaecological-Surgery) have done this for ALS in benign gynaecological procedures through the Gynaecological-Endoscopic-Surgical-Education and Assessment (GESEA). The curriculum is based on 5-pillars of competence(21). The ESGO/EBCOG/RCOG/NVOG as well as other national societies/institutes need to consider incorporating this into the accreditation criteria/requirements for GO training centres/programmes. 
The significantly lower training scores given by trainees to their training experience-\&-skills in ALS/RS compared to open surgery is a reflection of both limited access and also the quality of training imparted. It is likely to be an important factor for $>50 \%$ trainees wanting to go outside their training institute to enhance their ALS/RS skills. This compares unfavourably with the USA, where ALS, and RS are now well established in GO practice. In a recent update of the SGO survey indicated that $97 \%$ of US gynaecological oncologists performed RS to some extent, and $83 \%$ undertook ALS for oncological procedures.(22)

Although $75-84 \%$ trainees had read relevant literature and watched video recordings, for most training was not formalised/structured and lacked exposure to simulators/wet-lab/drylab models, use of logbooks and structured assessments (Table-2). Structured training also provides a better training environment and more effective feedback, the need for which has previously been reported.(8) Objective-structured-assessment of training(OSAT) evaluations have shown moderate correlations between bench-tests and performance in live animals (wet-lab) and the operating room.(23) Procedure-based assessments (PBA) have demonstrated high reliability in obstetrics-\&-gynaecology $(O \& G)$ and non-O\&G trainees.(24) Incorporation of laboratory surgical-training modules into a residency curriculum has been highly rated with similar OSATs scores seen in residents and those performing actual surgical cases.(25) Simulation platforms have shown construct, face and content validity for RS(26) and construct validity with ALS (Lap-Sim virtual reality simulator)..(27) The SAGESMIRA RS consensus group(20) and multidisciplinary group of urology-experts(28) also recommended incorporation of modular training, didactic, dry/wet-lab and simulation training, progressing to anonymised video assessment. Adoption of these into surgical education can facilitate standardization of training and assessment for introduction of new surgical techniques.

Although overall access is limited, the caseload of RS procedures performed in GO centers appears adequate (median=6.5cases/month or 75/annum) for delivering a RS training 
programme. The cases needed for the initial learning curve for proficiency in robotic hysterectomy for endometrial cancer with/without pelvic/para-aortic lymphadenectomy ranges from 20-33.(29-31) Additionally, efficiency improves with time/further practice.(31) The median number of cases performed by European trainees undergoing RS training was 24.5. Establishment of a RS programme needs to incorporate a period of robotic training for the entire theatre team including ODP, nurses and surgeons. The team needs to achieve proficiency in robotic set-up, port-placement, docking \& undocking, emergency undocking, instrumentation, disassembly and troubleshooting. A period of surgical mentorship by an experienced surgeon/proctor is also needed during the learning curve.(32) The Society of European-Robotic-Gynaecological-Surgery(SERGS) has outlined a pilot-curriculum in RS training targeting GO-trainees in the first instance. This pilot began in July-2015 and will be evaluated to develop a formal broad-based programme for RS training (personal communication). This is an important step towards potentially streamlining and bridging the training gap in RS for European GO trainees.(33)

Our findings that opportunities for minimal-access surgical training, formalized training schedules and logbooks are significantly more likely in accredited than non-accredited centers is consistent with previous reports highlighting the availability of better-quality training in accredited centers and emphasizes the need for center accreditation.(9) Accreditation ensures institutions maintain a minimal prescribed set of standards, case-load, infrastructural/organizational processes to facilitate training needs which in turn leads to a more affective training programme providing better supervision, coaching, assessment, feedback, team-work, and professional relationships.(8) It is also important for institutions, national GO organisations and training programme directors to institute mechanisms for monitoring the quality of $\mathrm{GO}$ training. A central European register for $\mathrm{GO}$ trainees is currently lacking and implementation of this would facilitate the monitoring \& evaluation of training as well as guide policy and support for training needs/skills. This is essential to achieve harmonization of GO-training across Europe. 
Our study has several strengths, including prospective collection, anonymised data, and broad representation of trainees from 30 European countries. It is limited by lack of qualitative data. However, it does provide an objective assessment of the state of ALS/RS training as perceived by trainees across Europe. Our findings highlight an important area of need for improving training in GO and should be of value to training institutions, ESGO, RCOG, NVOG and other organisers of training programmes in Europe. It can help guide policies and direct resources to further optimise training outcomes. Ultimately high-class training will produce better quality gynaecological oncologists which in turn should increase the quality of care received by women diagnosed with gynaecological cancer. 


\section{Tables}

Table 1. Basic demographics of respondents

\begin{tabular}{|c|c|c|}
\hline Demographics & & n (\%) \\
\hline Mean age in years $(\mathrm{SD})$ & & $35.2(6.1)$ \\
\hline Gender & $\begin{array}{l}\text { Female } \\
\text { Male }\end{array}$ & $\begin{array}{l}46 \text { (40.7) } \\
67 \text { (59.3) }\end{array}$ \\
\hline Mean Years in training (SD) & & $5.9(3.3)$ \\
\hline Which best describes your current post & $\begin{array}{l}\text { Sub-specialty fellow in GO (accredited post) } \\
\text { Research fellow in GO } \\
\text { Trainee in GO (non-accredited post) } \\
\text { Consultant Gynaecologist with special interest in } \\
\text { GO } \\
\text { Clinical academic fellow in GO }\end{array}$ & $\begin{array}{l}31(27.4) \\
13(11.5) \\
29(25.7) \\
30(26.5) \\
10(8.8)\end{array}$ \\
\hline Which field do you primarily work in & $\begin{array}{l}\text { Gynaecological Oncology } \\
\text { Medical Oncology } \\
\text { Obstetrics and Gynaecology } \\
\text { Others }\end{array}$ & $\begin{array}{l}61(54.0) \\
1(0.9) \\
49(43.4) \\
2(1.8)\end{array}$ \\
\hline ESGO member & $\begin{array}{l}\text { Yes } \\
\text { No }\end{array}$ & $\begin{array}{l}82(72.6) \\
28(24.8)\end{array}$ \\
\hline ENYGO member & $\begin{array}{l}\text { Yes } \\
\text { No }\end{array}$ & $\begin{array}{l}67 \text { (59.3) } \\
41(36.3)\end{array}$ \\
\hline \begin{tabular}{|l|} 
Degress currently held \\
\end{tabular} & $\begin{array}{l}\text { MD } \\
\text { PhD } \\
\text { MRCOG } \\
\text { MSc } \\
\text { MRCS }\end{array}$ & $\begin{array}{l}82(72.6) \\
30(26.5) \\
9(8.0) \\
14(12.4) \\
2(1.8)\end{array}$ \\
\hline Degree currently studying for & $\begin{array}{l}\text { MD } \\
\text { PhD } \\
\text { MRCOG } \\
\text { MSc } \\
\text { GO sub-spec accreditation } \\
\text { Other }\end{array}$ & $\begin{array}{l}24(21.2) \\
31(27.4) \\
3(2.7) \\
4(3.5) \\
33(29.2) \\
2(1.8)\end{array}$ \\
\hline Current post: & & \\
\hline Accredited training post & $\begin{array}{l}\text { Yes } \\
\text { No }\end{array}$ & $\begin{array}{l}52(46.0) \\
61(54.0)\end{array}$ \\
\hline ESGO recognition & $\begin{array}{l}\text { Yes } \\
\text { No }\end{array}$ & $\begin{array}{l}19(16.8) \\
94(83.2)\end{array}$ \\
\hline National society recognition & $\begin{array}{l}\text { Yes } \\
\text { No }\end{array}$ & $\begin{array}{l}49(43.4) \\
64(56.6)\end{array}$ \\
\hline
\end{tabular}




\begin{tabular}{|l|l|l|} 
Accreditation - other & Yes & $1(0.9)$ \\
& No & $112(99.1)$ \\
\hline $\begin{array}{l}\text { Country of training has accredited GO } \\
\text { sub-spec training programme }\end{array}$ & Yes & $68(60.2)$ \\
& No & $45(38.9)$
\end{tabular}

$n=$ total numbers $\%=$ overall percentage, $\mathrm{SD}=$ standard deviation, $\mathrm{GO}=$ Gynaecological oncology, $E S G O=$ European Society of Gynecological Oncology, ENYGO = European Network of Young Gynae Oncologists, MD = Medicinae Doctor, $\mathrm{PhD}=$ Doctorate of Philosophy, MRCOG $=$ Member of Royal College of Obstetricians and Gynaecologists, MSc $=$ Master of Science, MRCS $=$ Member of Royal College of Surgeons 
Table 2. Rating scores between surgical modalities

\begin{tabular}{|l|l|l|l|l|}
\hline & Open & $\begin{array}{l}\text { Advanced } \\
\text { Lap }\end{array}$ & Robotic & \\
\hline & & & & $\begin{array}{l}\text { p value (Kruskal- } \\
\text { Wallis) }\end{array}$ \\
\hline $\begin{array}{l}\text { Training [mean } \\
(\text { SD)] }\end{array}$ & $3.5(1.1)$ & $2.8(1.3)$ & $2.1(1.3)$ & $<0.005$ \\
\hline Skills [mean (SD)] & $3.3(1.0)$ & $2.6(1.1)$ & $1.9(1.2)$ & $<0.005$ \\
\hline
\end{tabular}

SD = Standard deviation 
Table 3. Comparison of training experience between advanced laparoscopic and robotic surgery

\begin{tabular}{|c|c|c|c|}
\hline Availability of ALS/RS & ALS n (\%) & RS n (\%) & p value \\
\hline $\begin{array}{l}\text { Institute undertakes advanced laparoscopic/robotic } \\
\text { surgery } \\
\text { Proportion of institutes offering sub-spec training in } \\
\text { ALS/RS where facility exists }\end{array}$ & $\begin{array}{l}76 / 112(67.9) \\
49 / 76(64.5)\end{array}$ & $\begin{array}{l}26 / 88(29.5) \\
10 / 26(38.5)\end{array}$ & $\begin{array}{l}<0.005 \\
0.02\end{array}$ \\
\hline \multicolumn{4}{|l|}{ Training structure in ALS/RS } \\
\hline Attended intermediate level workshop in ALS/RS & $38 / 113(33.6)$ & $5 / 113(4.4)$ & $<0.005$ \\
\hline Attended advanced level workshop in ALS/RS & $21 / 113(18.6)$ & $3 / 113(2.7)$ & $<0.005$ \\
\hline $\begin{array}{l}\text { Receiving/received formal training in current institute } \\
\text { of work in ALS/RS }\end{array}$ & $26 / 76(34.2)$ & $6 / 26(23.1)$ & 0.34 \\
\hline $\begin{array}{l}\text { Receiving/received formal training in institute other } \\
\text { than current place of work in ALS/RS }\end{array}$ & $13 / 113(11.5)$ & $3 / 113(2.7)$ & 0.02 \\
\hline Have completed training in ALS/RS & $6 / 113(5.3)$ & $2 / 113(1.8)$ & 0.28 \\
\hline $\begin{array}{l}\text { Reading relevant literature (articles, papers) on } \\
\text { ALS/RS }\end{array}$ & $70 / 90(77.8)$ & $36 / 43(83.7)$ & 0.50 \\
\hline Watching pre-recorded videos on ALS/RS & $76 / 90(84.4)$ & $33 / 44(75.0)$ & 0.24 \\
\hline Didactic sessions & $49 / 89(55.1)$ & $23 / 42(54.8)$ & 1.00 \\
\hline Online tutorials in ALS/RS & $32 / 89(36.0)$ & $13 / 41(31.7)$ & 0.70 \\
\hline $\begin{array}{l}\text { Standardised introduction to components and } \\
\text { functionality of surgical robots }\end{array}$ & & $25 / 43(58.1)$ & \\
\hline Dry lab practice with models in ALS/RS & $44 / 88(50.0)$ & $13 / 42(31.0)$ & 0.06 \\
\hline Wet lab animal models/cadaveric training in ALS/RS & $34 / 90(37.8)$ & $11 / 43(25.6)$ & 0.18 \\
\hline Training on virtual simulator in ALS/RS & $35 / 89(39.3)$ & $14 / 43(32.6)$ & 0.57 \\
\hline Availability of formal training schedule & $14 / 76(18.4)$ & $12 / 26(46.2)$ & 0.01 \\
\hline $\begin{array}{l}\text { Graduated step-wise progression of defined tasks } \\
\text { and steps under direct supervision of an expert in } \\
\text { ALS/RS }\end{array}$ & $29 / 76(38.2)$ & $15 / 26(57.7)$ & 0.08 \\
\hline Review of video recording and surgery & $30 / 81(37.0)$ & 14/36 (38.9) & 0.84 \\
\hline $\begin{array}{l}\text { Use of Objective structured assessment of training } \\
\text { (OSAT) to assess training in ALS/RS }\end{array}$ & $14 / 76(18.4)$ & $6 / 26(23.1)$ & 0.82 \\
\hline Use of logbooks for training progression in ALS/RS & $27 / 76(35.5)$ & $7 / 26(26.9)$ & 0.57 \\
\hline $\begin{array}{l}\text { GO surgical cases observed before part of/a } \\
\text { complete procedure [mean (SD)] } \\
\text { GO surgical cases assisted [mean (SD)] }\end{array}$ & $\begin{array}{l}29.6(45.2) \\
55.2(127.8)\end{array}$ & $\begin{array}{l}15.5(23.5) \\
25.9(38.3)\end{array}$ & $\begin{array}{l}0.01 \\
0.03\end{array}$ \\
\hline $\begin{array}{l}\text { Surgical cases performed as primary surgeon to date } \\
\text { [mean (SD)] }\end{array}$ & $31.6(92.9)$ & 24.5 (73.2) & 0.14 \\
\hline
\end{tabular}

$n=$ total numbers, $\%=$ overall percentage, $\mathrm{SD}=$ standard deviation, $\mathrm{ALS}=$ advanced laparoscopic surgery, $\mathrm{RS}=$ robotic surgery 
Table 4. Robotic surgical training in European institutes offering this facility

\begin{tabular}{|c|c|c|}
\hline Number of robots in institute & Mean (SD) & $1.6(1.9)$ \\
\hline \multirow[t]{4}{*}{ Number of institutes with different Robotic Systems } & Standard DaVinci & 13 \\
\hline & DaVinci S HD & 10 \\
\hline & DaVinci Si HD & 4 \\
\hline & Don't know & 6 \\
\hline Years robots used at institution & Mean (SD) & $3.7(1.8)$ \\
\hline $\begin{array}{l}\text { Number of disciplines other than gynae-oncology that uses } \\
\text { robots }\end{array}$ & Mean (SD) & $2.1(1.3)$ \\
\hline $\begin{array}{l}\text { Gynae-oncologists undertake robotic surgery in your institute } \\
(\%)\end{array}$ & & $21 / 26(80.8)$ \\
\hline Number of GO surgeons using robots in your institute & Mean (SD) & $2.6(1.5)$ \\
\hline Number of GO procedures performed/month using robots & Mean (SD) & $6.5(5.3)$ \\
\hline Dual console used during training & & $8 / 26(30.8)$ \\
\hline Practiced on robotic system when attended conference(s) & & $8 / 113(7.1)$ \\
\hline $\begin{array}{l}\text { Training in robotic surgery is part of general gynae training } \\
(\%)\end{array}$ & & $7 / 27(25.9)$ \\
\hline How many robotic surgery trainers in your institute & Mean (SD) & $1.9(0.6)$ \\
\hline $\begin{array}{l}\text { Trainees undergoing robotic surgical training in GO at your } \\
\text { institute }\end{array}$ & Mean (SD) & $1.7(0.7)$ \\
\hline Trainees who teach robotic surgery in GO (\%) & & $4 / 26(15.4)$ \\
\hline
\end{tabular}

$\mathrm{SD}=$ Standard deviation, standard DaVinci/DaVinci S HD/DaVinci Si HD = Different robotic surgical systems by Intuitive Surgical (Sunnyvale, California, USA) 


\section{References:}

1. Dargent D. Laparoscopic surgery and gynecologic cancer. Curr Opin Obstet Gynecol 1994;5:294-300

2. Querleu D, Leblanc E, Castelain B. Laparoscopic pelvic lymphadenectomy in the staging of early carcinoma of the cervix. Am J Obstet Gynecol $1991 ; 164: 579-581$

3. www.investor.intuitivesurgical.com/phoenix.zhtml. Accessed on 15 July 2015

4. Gaia G, Holloway RW, Santoro L et al. Robotic-assisted hysterectomy for endometrial cancer compared with traditional laparoscopic and laparotomy approaches - a systematic review. Obstet Gynecol 2010;116(6):1422-1431

5. Wright JD, Herzog TJ, Neugut Al et al. Comparative effectiveness of minimally invasive and abdominal radical hysterectomy for cervical cancer. Gynecol Oncol 2012;127(1):11-17

6. Vernooij F, Heintz P, Witteveen E et al. The outcomes of ovarian cancer treatment are better if provided by gynecologic oncologists and in specialized hospitals: A systematic review. Gynecol Oncol 2007;(3):801-812

7. Munstedt K, von Georgi R, Misselwitz B et al. Centralising surgery for gynecologic oncology - A strategy assuring better quality treatment? Gynecol Oncol 2003;89(1):4-8

8. Piek J, Bossart M, Boor $\mathrm{K}$, et al. The work place educational climate in gynecological oncology fellowships across Europe: the impact of accreditation. Int J Gynel Cancer 2015;1:180-190

9. Manchanda R, Godfrey M, Wong-Taylor LA et al. The need for accredited training in gynaecological oncology: a report from the European Network of Young Gynaecological Oncologists (ENYGO). Ann Onc 2012;1-9

10. Gultekin M, Dursun P, Vranes B, et al. Gynecologic oncology training systems in Europe: A report from the European Network of Young Gynaecological Oncologists. Int J Gyne Cancer 2011;21:1500-1506

11. Gultekin M, Dursun P, Vranes B et al. Gynecologic oncology training systems in Europe: a report from the European network of young gynaecological oncologists. Int J Gynecol Cancer. 2011;21: 1500-6.

12. Gultekin M, Manchanda R. Training in Gynaecologic Oncology across Europe. In: A. Ayhan NR, M. Gultekin, P. Dursun, ed. Textbook in Gynaecological Oncology, 2nd edition: Gunes Publishing 2011:1103-14.

13. Advincula AP, Wang K. Evolving role and current state of robotics in minimally invasive gynecologic surgery. J Minim Invasive Gynecol. 2009;16(3):291-301 
14. Marino P, Houvenaeghel G, Narducci F et al. Cost-effectiveness of conventional vs. robotic-assisted laparoscopy in gynecologic oncology indications. Int J Gynecol Canc. 2015;25(6):1102-1108

15. lavazzo C, Papadopoulou E, Gkegkes I. Cost assessment of robotics in gynecologic surgery: A systematic review. J Obstet Gynaecol Research. 2014;40(11):2125-2134

16. Wright K, Jonsdottir G, Jorgensen $\mathrm{S}$ et al. Costs and outcomes of abdominal, vaginal, laparoscopic and robotic hysterectomies. JSLS. 2012;16:519-524

17. Ramirez PT, Adams S, Boggess JF et al. Robotic-assisted surgery in gynecologic oncology: a Society of Gynecologic Oncology consensus statement. Developed by the Society of Gynecologic Oncology's Clinical Practice Robotics Task Force. Gynecol Oncol. 2012;124: 180-4.

18. Schreuder HWR, Wolswiji R, Zweemer RP et al. Training and learning robotic surgery, time for a more structured approach: a systematic review. BJOG 2012;119:137-149

19. Marino P, Houvenaeghel G, Narducci F et al. Cost-Effectiveness of Conventional vs Robotic-Assisted Laparoscopy in Gynecologic Oncologic Indications. Int J Gynecol Cancer. 2015;25: 1102-8.

20. Heron DM, Marohn M. A consensus documentation on robotic surgery. Surg Endosc 2008;22:313-325

21. http://www.esge.org/images/GESEA PROGRAM/GESEA 2013 FINAL/PDF/ GESEA folder FINAL\%20BERLIN.pdf. Accessed $2^{\text {nd }}$ September 2015.

22. Conrad LB, Ramirez PT, Burke W et al. Role of minimall invasive surgery in gynecologic oncology: An updated survey of members of the Society of Gynecologic Oncology. Int J Gynecol Cancer 2015;25(6):1121-1127

23. Martin JA, Regehr G, Reznick R et al. OSATS for surgical residents. Br J Surg 1997;84:273-278

24. Beard JD, Jolly BC, Newble $P$ et al. Assessing the technical skills of surgical trainees. Br J Surg 2005;92:778-782

25. Goff B. Changing the paradigm in surgical education. Am Obstet Gynecol 2008;112(2):328-332

26. Abboudi $\mathrm{H}$, Khan MS, Abourmarzouk $\mathrm{O}$ et al. Current status of validation for robotic surgery simulators - a systematic review. BJU Int 2013;111:194-205 
27. van Hove PD, Tuijthof GJM, Verdaasdonk EGG, et al. Objective assessment of technical surgical skills. Br J Surg 2010;97(7):972-987

28. Ahmed K, Khan R, Mottrie A et al. Development of a standardized training curriculum for robotic surgery: a consensus statement from an international multidisciplinary group of experts. BJU Int 2015;116:93-101

29. Lim P, Kang E, Park DH. Learning curve and surgical outcome for roboticassited hysterectomy with lymphadenectomy: case-matched controlled comparison with laparoscopy and laparotomy for treatment of endometrial cancer. J Minim Invasive Gynecol. 2010;17(6):739-748

30. Sandadi S, Gadzinski JA, Lee S, et al. Fellowship learning curve associated with completing a robotic assisted total laparoscopic hysterectomy. Gynecol Oncol 2014;132:102-106

31. Lau S, Vaknin Z, Ramana-Kumar AV, Halliday D et al. Outcomes and cost comparisons after introducing a robotics program for endometrial cancer surgery. Obstet Gynecol. 2012;119(4):717-724

32. Madhuri TK, Hamzawala I, Tailor A et al. Robot assisted surgery in gynecologic oncology - starting a program and initial learning curve from a UK tertiary referral centre: the Guildford perspective. Int J Med Robotics Comput Assist Surg 2012;8:496-503

33. www.sergs.org/fellowship-programme. Accessed on 20 September 2015. 


\section{Table legends:}

Table 1 - Basic demographics of respondents

Table 2 - Rating scores between surgical modalities

Table 3 - Comparison of training experience between advanced laparoscopic and robotic surgery

Table 4 - Robotic surgical training in European Institutes offering this facility

Supplementary table 1 - Survey questionnaire on advanced laparoscopic and robotic surgery sent to European gynaecological oncology trainees

Supplementary table 2 - Questionnaire development

Supplementary table 3 - Trainees from corresponding country of training who responded to survey

Supplementary table 4 - Procedures suggested by trainees to be replaced by robotic surgery 